\title{
Cloud computing based e-government in Iraq using partial least square algorithm
}

\author{
Hayder Salah Hashim, Zainab Amin Al-Sulami
}

University of Basrah, Basrah, Iraq

\begin{tabular}{|c|c|}
\hline Article Info & ABSTRACT \\
\hline Article history: & \multirow{8}{*}{$\begin{array}{l}\text { The electronic government (e-government) worldwide is slowly progressing. } \\
\text { The e-government progress in developing countries, such as Iraq, is slower } \\
\text { compared with those of regional countries. Prior research suggested } \\
\text { deploying cloud based e-government (CBEG). However, most studies are } \\
\text { either review or conceptual. This study aims to examine the CBEG in Iraq } \\
\text { and identify the criteria that are required for utilizing this technology. A total } \\
\text { of } 279 \text { academic staff working in the IT department in Iraqi universities have } \\
\text { participated in this study. The findings using matrix and the algorithm of } \\
\text { partial least square presented ten criteria. After using the average variance } \\
\text { extracted technique, the criteria reduced to seven. Further analysis using } \\
\text { smart partial least square was conducted, and this resulted in five important } \\
\text { criteria namely, reliability of the service followed by availability, security, } \\
\text { trust, and technological competence. Decision makers have to increase the } \\
\text { competence of the staff and enhance the CBEG services. }\end{array}$} \\
\hline Received Dec 3, 2020 & \\
\hline Revised Mar 16, 2021 & \\
\hline Accepted Mar 21, 2021 & \\
\hline Keywords: & \\
\hline Algorithm & \\
\hline Cloud based e-government & \\
\hline Partial least square & \\
\hline
\end{tabular}

This is an open access article under the CC BY-SA license.

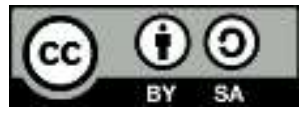

Corresponding Author:

Hayder Salah Hashim

Basrah University, Basrah, Iraq

Email: hayder_alasadi@uobasrah.edu.iq

\section{INTRODUCTION}

The electronic government (E-government) was developed to speed the service delivered to citizens. The project aimed to shift the governmental organisations toward a citizen-centric one and provide large routinely services via the online platforms [1]-[2]. The services that were provided by the E-government have become outdated with the advancement in technology and the introduction of big data, and citizens are looking for interactive and useful services [3]-[6]. In this process, some countries, such as Japan, united states (US) and Singapore, have made progress in shifting the E-government to cloud environment to achieve the scalability and provide services to citizens [7]-[9].

The united nations (UN) classified the development of E-government into five stages. Most developed countries reached the maturity stage, which is the last stage. In developing countries, the progress is still in the second stage with merely providing information about the services rather than conducting and executing them to citizens. For example, the E-government website in Iraq provides a description of the services and the procedures of obtaining some documents rather than providing the document itself [10].

The UN e-government survey in 2018 reported that Iraq is in the 155th rank. The regional countries, such as Iran, is in the 86th rank, Saudi Arabia is in the 52nd rank, and Jordan is in the 98th rank. This finding shows that the Iraqi E-government is far beyond the regional countries. By contrast, several studies suggest the move to cloud-based e-government (CBEG) to overcome the challenges of developing E-government project and achieve high efficiency of providing services to citizens [10].

Cloud computing (CC) has emerged during the last decade, and it provides several advantages for individuals, organisations and government. This initiative can be the solution that the government is looking 
for to reduce the cost of operating E-government and enhance the services and efficiency of the governmental services [11]. Understanding the predictors of CC usages could help in securing a smooth shift from traditional E-government to CBEG.

In this regard, researchers attempted to investigate the adequacy and suitability of existing frameworks to provide decision makers with a roadmap to move from traditional to CBEG. Nevertheless, the previous studies looked into the issue either from the individual or organisational perspective. Given that the topic is still new, and insights toward the effective implementation of CBEG are scarce, a comprehensive framework, such as the technological-organisational-environmental (TOE) framework, that considers the multiple perspectives of using a new technology is needed. However, few previous studies attempted to use this framework to understand the shift toward CBEG.

This study aims to look into the issue of CBEG and the contributing predictors that facilitate such move by using the partial least square algorithm. The rest of this work discusses the literature review, research methodology, findings of PLS algorithm, discussion and conclusion.

\section{LITERATURE REVIEW}

\subsection{E-government in Iraq}

Explaining the UN reported that countries are making progress in developing the E-government projects. However, this progress varied among countries. Some countries look into the smart government and CBEG, while others are still struggling with the online presence. In the case of Iraq, the project was launched in collaboration with the Italian government in 2004. However, only a small progress was achieved since 2004 [12]-[13]. The E-government in Iraq has online presence, but it does not provide any interactive services, such as the two-way communication or the ability to obtain legal document. Iraq is behind most regional countries in the development of E-government project [10].

Iraq is far behind all countries, and the development of E-government index is the lowest among all regional countries. The slow development could be attributed to several factors, including organisational, technological and environmental factors [13]-[14]. The E-government human capital is critical for the development of E-government from the organisational perspective. From the technological perspective, the infrastructure and perception about security, privacy and the internet connection could play important roles in developing the E-government. From the environmental perspective, the legislation of government and the pressure of citizens and employees are also determining predictors of the development of E-government [12], [15]. Nevertheless, several studies examined the E-government projects and suggested that moving to CC will resolve several issues, such as the quality of the services, and the problem of infrastructure, security and privacy.

\subsection{CBEG}

The use of advance technology can increase the efficiency and performance of entities, such as organisations and governments [16]. The cloud-based E-government has been suggested as a solution to speed the progress of the development of E-government. However, most studies are either conceptual or a literature review. For example, the usage of CBEG was reviewed in the study of [17], who examined the benefit and challenges of moving to CBEG. Paliwal and Keswan [18] reported that the benefits and challenges were reviewed. The trust and security of the CBEG were reviewed in the study of [19], and a model of trust security was proposed. The findings in the study of [20] indicated that infrastructure, availability and trust are critical for the use of CBEG. Mohammed et al. [21] reviewed the literature and pointed out the lack of the studies on CBEG. The validity of the questionnaire of CBEG was tested in the study of [22].

Few empirical studies were conducted to examine the CBEG. The study of [23] examined the usage of CBEG in China among public organisations. The findings indicated the five categories that contribute to the development and progress of CBEG. These categories include the cloud providers, technology, readiness, trust and technology driven. The cost of E-government and the need for scalability are the main drivers for the use of CBEG [24]. The study of [25] examined the usage of CBEG among public organisations and showed several drivers for the use of CBEG. These drivers include diffusion of innovation attribute, security, IT policy, infrastructure, asset specificity and return on investment, which has an essential effect on the viability of using the CBEG. The summary of the latest articles in the CDEG is illustrated in Table 1 . The aforementioned table illustrates that most studies were review of the literature. Studies on CBEG are also scarce [21]. Previous studies also did not holistically look on the usage of CBEG. Thus, the following section discusses the usage of TOE framework. 
Table 1. Summary of the selected studies

\begin{tabular}{|c|c|c|c|}
\hline Author/year & Country & Approach & Finding \\
\hline$[23]$ & $\begin{array}{l}\text { A study of public organisation in } \\
\text { China }\end{array}$ & Case study & $\begin{array}{l}\text { The attributes to the CBEG can be categorized as } \\
\text { cloud providers, the technology, readiness, trust and } \\
\text { technologically driven. }\end{array}$ \\
\hline [17] & CBEG & Literature review & Several benefits from adopting CBEG \\
\hline [24] & General & Case study & $\begin{array}{l}\text { The main predictors of CBEG are the saving in cost } \\
\text { and the scalability. }\end{array}$ \\
\hline$[22]$ & Yemen/public organisation & Developing a measurement & $\begin{array}{l}\text { Pilot testing was conducted to examine the validity } \\
\text { of the measurement. }\end{array}$ \\
\hline [25] & Yemen/public organisation. & $\begin{array}{l}\text { Quantitative approach } \\
\text { using a questionnaire }\end{array}$ & $\begin{array}{c}\text { The organisational and governmental aspects and the } \\
\text { viability of the CBEG are critical for the } \\
\text { implementation of CBEG. }\end{array}$ \\
\hline [19] & General & Review & $\begin{array}{l}\text { The study proposed a security trust model for } \\
\text { Cloudlet for E-government web services. }\end{array}$ \\
\hline [26] & Indonesia/local government & Questionnaire & $\begin{array}{l}\text { Performance expectancy and expectation availability } \\
\text { have positive effects. }\end{array}$ \\
\hline$[20]$ & $\begin{array}{l}\text { Developing countries/issue and } \\
\text { challenges of adoption of CBEG }\end{array}$ & Review & $\begin{array}{c}\text { IT infrastructure, availability and trust are critical for } \\
\text { the use of CBEG. }\end{array}$ \\
\hline [18] & General & Review & $\begin{array}{l}\text { The study reviewed the benefits and challenges of } \\
\text { using CBEG. }\end{array}$ \\
\hline [21] & General & Review & Studies that deal with CBEG are lacking. \\
\hline
\end{tabular}

\subsection{TOE}

The TOE is one of the known frameworks that has been widely used in investigating the technology, innovation and the usage of the new system. The framework consists of three groups of variables. The first group consists of the technological factors, such as security, privacy and availability. The organisational factors include various indicators, such as the management support and size and capabilities of the organisation. The environmental factors include indicators, such as the legislation, external pressure and competition. Several studies implemented the TOE to understand the situation of technological usages. Tashkandi and Al-jabri [27] examined the adoption of CC by using TOE and found that improving the internet connection and availability and addressing the concerns of privacy and security are important predictors in enhancing the usage of CC among students in Saudi Arabia. Aatif, et al., [28] examined the usage of TOE in cloud government services and found that the model can be used in this context.

Wang, et al., [29] examined the barriers and benefits of CBEG for organisational use and concluded that the organisational, environmental and technological characteristics affect the usage of CBEG. In Iraq, [11] examined the usage of CBEG and proposed a conceptual framework for decision makers that includes the technological, environmental and organisational contexts and ease of use and legal issue. In this study, the TOE is examined, and it includes the technological, environmental and organisational perspectives. The technological perspective includes the relative advantage, ease of use, compatibility and reliability. The organisational perspective includes the cost, top management support and technological readiness. The environmental perspective includes the trust, security and availability.

\section{RESEARCH METHODOLOGY}

This study aims to understand the critical steps that lead to smooth and viable shifting toward the CBEG. The population of this study must be carefully selected to efficiently understand this phenomenon. The academic staff in the IT department in the Iraqi universities are selected as the population of this study. The sample of this study consists of almost 35,000 academic staff. However, out of the 35,000-academic staff, 6500 of them are from the IT department. In choosing the sampling based on [30], the sample size is 363.

A questionnaire was developed on the basis of the previous studies, and the TOE framework was incorporated to understand the predictors. The measurements of the questionnaire were adopted from several researchers [31]-[35]. A total of 363 questionnaires were distributed to the academic staff in all states of Iraq. Approximately $43 \%$ of the questionnaires were distributed in the universities in Baghdad, which is the capital of Iraq, because more than 14,680 academic staff are working in Baghdad out of which 3000 are IT academic staff. Accordingly, 219 questionnaires were collected from the respondents. No missing value was observed because all questions were labelled as 'required'. Exploratory factor analysis was conducted to assess the relatedness of the variables. 


\section{FINDINGS}

The profile of the respondents is illustrated in Table 2. Majority of the respondents are males $(81.2 \%)$, and their ages are less than 45 years old (73.9\%). Moreover, majority of the $71.8 \%$ of respondents are holders of PhD degree and have experience of less than 22 years (71.5\%). Table 2 shows the background information of the respondents.

Table 2. Background information of the respondents

\begin{tabular}{cccc}
\hline Variable & Label & Frequency & Percent \\
\hline Gender of the respondents & Male & 178 & 81.2 \\
& Female & 41 & 19.8 \\
Age group of the respondents & Less than 35 years old & 63 & 28.7 \\
& 36-45 years old & 99 & 45.2 \\
Highest level of education & More than 45 years old & 57 & 26.1 \\
& Master's degree & 64 & 29.2 \\
Experience as academic staff & PhD degree & 155 & 71.8 \\
& Less than 7 years & 33 & 15.0 \\
& From 7 years to 14 years & 43 & 19.6 \\
& From 15 years to 22 years & 81 & 36.9 \\
& From 23 years to 30 years & 23 & 10.5 \\
& More than 30 years & 39 & 18.0 \\
\hline
\end{tabular}

\subsection{Important criteria for the CBEG}

Table 4 shows the weight for the criteria. The most important criteria are the compatibility and ease of use of the CBEG, followed by trust and technology competency. These criteria can be categorized under three constructs as shown in Table 3. An exploratory factor analysis (EFA) was conducted to assess the loading of the variables and the items. The finding as shown in the scree plot in Figure 1 indicate that there are seven components.

Table 3. Important criteria based on the answers of the respondents

\begin{tabular}{ccc}
\hline No. & Criteria & Construct \\
\hline 1 & Compatibility and ease of use & Technological \\
2 & Trust & Environmental \\
3 & Technological competency & Organisational \\
4 & Security & Environmental \\
5 & Privacy & Environmental \\
6 & Relative advantage & Technological \\
7 & Availability & Environmental \\
8 & Cost & Organisational \\
9 & Top management support & Organisational \\
10 & Reliability & Technological \\
\hline
\end{tabular}

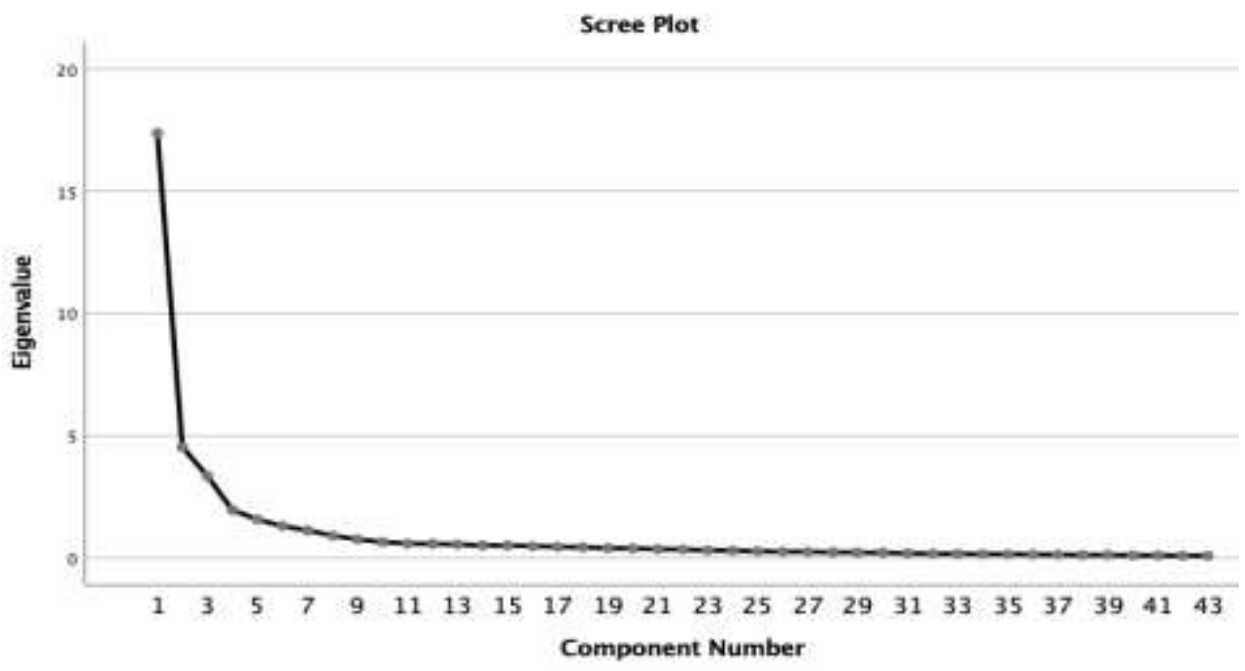

Figure 1. Scree plot of EFA 
Further to confirm the results, of EFA, the technique of the measurement model was used to filter the important criteria on the basis of the PLS logarithm. The average variance extracted (AVE) was calculated on the basis of the formula given by [36]. The AVE is a measurement of the goodness and the representation of the criteria to the topic, and in this case, it is the CBEG. Table 4 illustrates that some criteria were dropped due to low AVE, which is acceptable if the value is greater than 0.50 . The most critical criterion for the CBEG is the technological competence of the staff of CBEG, followed by the reliability, compatibility and ease of use, cost, trust, availability and security. Structural model was used to examine the casual effect of the refined variables. Figure 2 shows the results of testing the casual effect of the proposed variable. From Figure 2, it can be seen that the most critical criterion for the CBEG is the reliability of the service followed by availability, security, trust, and technological competence. Other criterion such as the compatibility and the cost were not highly significant.

Table 4. AVE of the criteria

\begin{tabular}{cc}
\hline Criteria & AVE \\
\hline Technological competence & 0.94 \\
Reliability & 0.90 \\
Compatibility and ease of use & 0.88 \\
Cost & 0.85 \\
Trust & 0.81 \\
Availability & 0.79 \\
Security & 0.71 \\
\hline
\end{tabular}

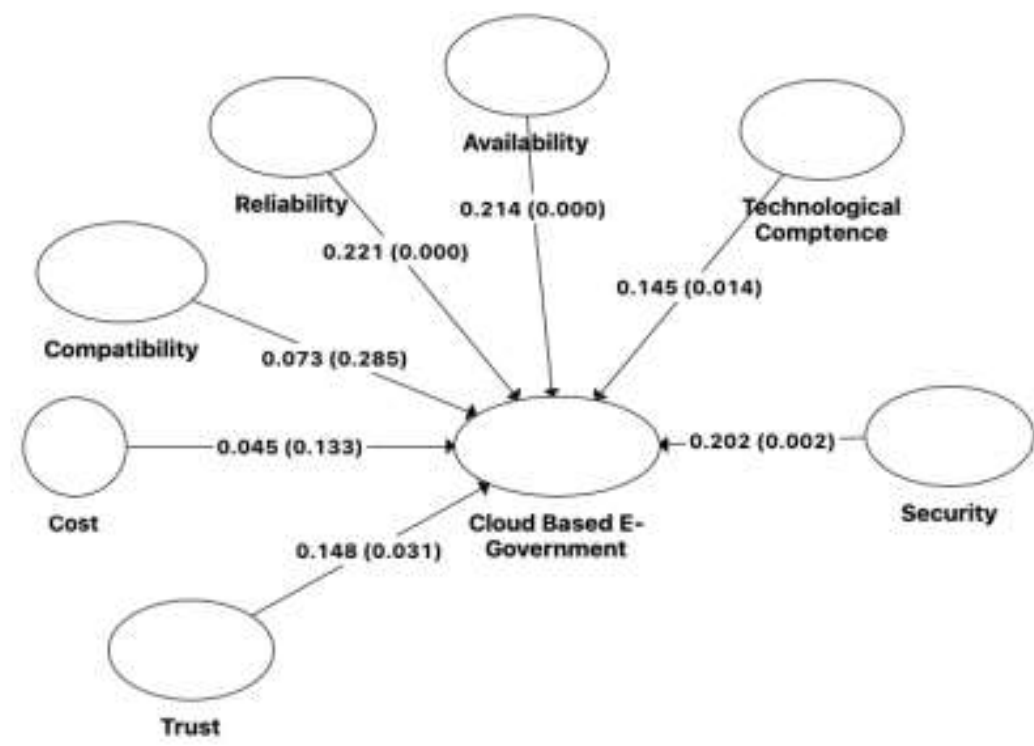

Figure 2. Results of testing the outcome of AVE

\section{DISCUSSION}

This study aimed to investigate the CBEG in Iraq. The E-government development in Iraq is far beyond the regional countries. Existing studies were reviewed on the basis of the literature. The result showed that studies that empirically deal with the CBEG are scarce. Accordingly, the study collected data from academic staff working in Iraqi IT department. The findings indicated that the critical criteria for the usage of CBEG are technological competence, reliability, compatibility and ease of use, cost, trust, availability and security. Then the criteria were further filtered using the technique of Smart PLS. The final outcome showed that the essential criteria for the usage of CBEG in Iraq are the reliability of the service, availability, security, trust, and technological competence. The above-mentioned findings regarding the criteria are in line with those of previous studies that have investigated the usages of CBEG.

The study also found that the predictors can be divided into constructs or categories. Previous studies found that reliability and trust are important predictors of the usage of CBEG [20], [26]. Other studies refer to the importance of security in the usage of the CBEG [24]. In line with the TOE framework, [23] 
found the important predictors, and they can be divided into categories. Technological competence is critical for the deployment of CBEG. The staff must be highly qualified and prepared to deal with the CBEG.

The services that are offered by the CBEG must be reliable and officially authorized by the government to ensure that citizens can conduct their business by using only the CBEG. The final outcome showed that compatibility and cost were not significant criteria for the CBEG. This could be due to the notion that CBEG provides infrastructure, software and hardware on demand basis. This makes the cost and compatibility not critical compared to other criteria [22], [37].

Trust is critical and has several sides [38]. First, the operators of CBEG must trust the cloud provider. The citizens or users of CBEG must trust the government and the Internet. The availability of the services and their accessibility anywhere at any time are among the essential criteria [39]-[40]. In all these criteria, the security of the transactions is a highly critical criterion for the utilisation of CBEG [41], [19].

\section{IMPLICATION}

The theoretical and practical contributions were derived from this study. First, the study enriches the literature of CBEG because the studies that have been conducted are limited to review and conceptual work. The study examined the CBEG in developing countries, such as Iraq; thus, it has contributed to this regard. The study also contributed to the literature as regards using the TOE as a theoretical framework to understand the usage of CBEG. Few studies have carried out such initiative and utilized the TOE.

The study found that the common critical criterion for the CBEG for practical implication is the technological competence. Employees at the public organisation have to be knowledgeable about the application of $\mathrm{CC}$ and the use the cloud in E-government environment. Accordingly, decision makers are advised to conduct workshops and courses to enhance the technological competence of employee. Training is also a useful tool to improve the technological competence.

The reliability and executability of the services are important criteria for the use of CBEG. Decision makers are advised to minimize the error and increase the efficiency of the CGEG to provide reliable services. From the organisational or governmental perspective, the compatibility and cost of CBEG are important criteria. However, the easiness of conducting transactions by using the CBEG is also important from the users' perspectives.

A critical criterion is the trust in the CBEG. This trust has two parts: trust of the employees in running the CBEG and trust of users on the Internet and in the government to keep their information safe and protected from intruders or access by third party. The availability of the cloud services and the ability to access the services anywhere at any time are important for users. Thus, the infrastructure in the country must be improved in terms of the internet connection, access and internet speed to allow wide availability of the CBEG services. The last criterion is the security of the CBEG services. Decision makers have to ensure that the data are safe and away from criminals and predators. Strong measures have to be applied to secure the CBEG and make it safe for doing transactions by users.

\section{CONCLUSION}

This study was conducted to examine the predictors of CBEG. The study deployed a population of academic staff in Iraqi IT departments. The study collected data from 279 respondents. Accordingly, the findings are limited to the perception of the academic staff. The study also deployed the TOE framework and examined the technological, organisational, and environmental perspectives. Further refinement of the criteria in TOE framework was conducted to come up with the most critical predictors of CBEG. This has resulted in reliability of the service followed by availability, security, trust, and technological competence as the most important criteria for CBEG. Future research should examine the practices of CBEG in different countries and populations. Regional countries must be studied because the progress of E-government is also slower compared with those of the developed world. The insights of other stakeholders, such as IT professional, decision makers and users of the CBEG, should also be considered. Several frameworks can be used in future studies. The IT success model, technological acceptance model and social exchange theory can be used in explaining the variation of using CBEG. Thus, future research is recommended to deploy these models and theories in improving the understanding of CBEG. Decision makers can use the findings of this study to foster the development of E-government project in Iraq and to focus on the criteria that can lead to successful usage of CBEG in the country. 


\section{REFERENCES}

[1] D. Špaček, M. Csótó, and N. Urs, "Questioning the Real Citizen-Centricity of e-Government Development: Digitalization of G2C Services in Selected CEE Countries," NISPAcee J. Public Adm. Policy, vol. 13, no. 1, pp. 213-243, 2020, doi: 10.2478/nispa-2020-0009.

[2] K. Kasemsap, "The roles of business process modeling and business process reengineering in e-government," in Open Government: Concepts, Methodologies, Tools, and Applications, IGI Global, pp. 2236-2267, 2020, doi: 10.4018/978-1-4666-8833-9.ch015.

[3] A. Bhawiyuga, S. A. Kharisma, B. J. Santoso, D. P. Kartikasari, and A. P. Kirana, "Cloud-based middleware for supporting batch and stream access over smart healthcare wearable device,” Bull. Electr. Eng. Informatics (BEEI), vol. 9, no. 5, pp. 1990-1997, 2020, doi: 10.11591/eei.v9i5.1978.

[4] S. Zaineldeen and A. Ate, "Improved cloud data transfer security using hybrid encryption algorithm," Indones. J. Electr. Eng. Comput. Sci. (IJEECS), vol. 20, no. 1, pp. 521-527, 2020, doi: 10.11591/ijeecs.v20.i1.pp521-527.

[5] P. R. Joshi and S. Islam, "E-Government Maturity Model for Sustainable E-Government Services from the Perspective of Developing Countries," Sustainability, vol. 10, no. 6, p. 1882, 2018, doi: 10.3390/su10061882.

[6] R. Kumar, A. Sachan, and A. Mukherjee, "Qualitative approach to determine user experience of e-government services,” Comput. Human Behav., vol. 71, pp. 299-306, 2017, doi: 10.1016/j.chb.2017.02.023.

[7] Y. Liang, G. Qi, K. Wei, and J. Chen, "Exploring the determinant and influence mechanism of e-Government cloud adoption in government agencies in China," Gov. Inf. Q., vol. 34, no. 3, pp. 481-495, 2017, doi: 10.1016/j.giq.2017.06.002.

[8] S. Patil and N. Chaudhari, "Use of Cloud Computing \& Automation for E-Government in India: Challenges and Benefits,” Int. J. Eng. Manag. Res., vol. 7, no. 1, pp. 316-321, 2017.

[9] U. Anwar, H. A. Umair, A. Sikander, and Z. U. Abedin, "Government Cloud Adoption and Architecture," in 2019 2nd International Conference on Computing, Mathematics and Engineering Technologies (iCoMET), pp. 1-8, 2019, doi: 10.1109/ICOMET.2019.8673457.

[10] United Nations, E-Government Survey 2018. 2018.

[11] B. S. Shukur, M. K. A. Ghani, and M. A. Burhanuddin, "An analysis of cloud computing adoption framework for Iraqi e-government," Int. J. Adv. Comput. Sci. Appl., vol. 9, no. 8, pp. 104-112, 2018, doi: 10.14569/IJACSA.2018.090814.

[12] H. S. Hashim and Z. Bin Hassan, "Factors that influence the users' adoption of cloud computing services at Iraqi Universities: An empirical study,” Aust. J. Basic Appl. Sci., vol. 9, no. 27, pp. 379-390, 2015.

[13] H. S. Hashim, Z. Bin Hassan, and A. S. Hashim, "Factors influence the adoption of cloud computing: A comprehensive review," Int. J. Educ. Res., vol. 3, no. 7, pp. 296-306, 2015.

[14] Z. A. Al-Sulami and H. S. Hashim, "Review of Key Performance Indicators to Evaluate the Tacit Knowledge Performance of the Academicians," J. Basrah Res., vol. 46, no. 1, 2020.

[15] A. D. Noor, H. S. Hashim, and N. Ali, "Factors influencing knowledge sharing in organizations: A literature review," Int. J. Sci. Res., vol. 3, no. 9, pp. 1314-1319, 2014.

[16] S. Alaaraj, "Knowledge Management Capabilities, Trust, and Performance of Manufacturing Companies in Emerging Economies," in Proceedings of 177 th The IIER International Conference, pp. 1-9, 2018.

[17] T. Almarabeh, Y. K. Majdalawi, and H. Mohammad, "Cloud Computing of E-Government," Commun. Netw., vol. 8, no. 8, pp. 1-8, 2016, doi: 10.4236/cn.2016.81001.

[18] N. Paliwal and B. Keswani, "Cloud Computing Adoption in the E-Government Perspective : A Review," Tathapi UGC Care J., vol. 19, no. 2, 2020.

[19] B. Al-Shargabi, S. Al-Jawarneh, and S. M. A. Hayajneh, "A cloudlet based security and trust model for egovernment web services," J. Theor. Appl. Inf. Technol., vol. 98, no. 1, pp. 27-37, 2020.

[20] N. Al Mudawi, N. Beloff, and M. White, "Issues and challenges: Cloud computing e-government in developing countries," Int. J. Adv. Comput. Sci. Appl., vol. 11, no. 4, pp. 7-11, 2020, doi: 10.14569/IJACSA.2020.0110402.

[21] F. Mohammed, F. Olayah, A. Ali, and N. A. Gazem, "The effect of cloud computing adoption on the sustainability of e-government services: A review," Int. J. Adv. Sci. Technol., vol. 29, no. 5, pp. 2636-2642, 2020.

[22] F. Mohammed, O. Ibrahim, and N. Ithnin, "Factors influencing cloud computing adoption for e-government implementation in developing countries," J. Small Bus. Enterp. Dev., vol. 18, no. 3, pp. 297-327, 2016, doi:10.1108/JSIT-01-2016-0001.

[23] Y. Liang, G. Qi, K. Wei, and J. Chen, "Exploring the determinant and influence mechanism of e-Government cloud adoption in government agencies in China," Gov. Inf. Q., no. 27, pp. 0-1, 2017, doi: 10.1016/j.giq.2017.06.002.

[24] F. Mohammed and O. Bin Ibrahim, "Drivers of Cloud Computing Adoption for E-Government Services Implementation," Int. J. Distrib. Syst. Technol., vol. 6, no. 1, pp. 1-14, 2015, doi: 10.4018/ijdst.2015010101.

[25] F. Mohammed, O. Ibrahim, M. Nilashi, and E. Alzurqa, "Cloud computing adoption model for e-government implementation," Inf. Dev., vol. 33, no. 3, pp. 303-323, 2016, doi: 10.1177\%2F0266666916656033.

[26] N. S. A. Restu and S. Ali, "Determining Factors of Cloud Computing Adoption: A Study of Indonesian Local Government Employees," J. Account. Invest., vol. 21, no. 2, 2020, doi: 10.18196/jai.2102151.

[27] A. Tashkandi and I. M. Al-jabri, "Cloud Computing Adoption by Higher Education Institutions in Saudi Arabia," IEEE, 2015, doi: 10.1007/s10586-015-0490-4.

[28] M. Aatif, B. Hayat, Y. Mahmood, S. Nawaz, K. Hameed, and S. Tabassum, "Determinants Impacting the Adoption of E-Government Information Systems and Suggesting Cloud Computing Migration Framework," Int. J. Adv. Comput. Sci. Appl., vol. 8, no. 9, 2017, doi: 10.14569/JJACSA.2017.080925. 
[29] W. Wang, Y. Liu, Y. Liang, and K. He, "The Influential Factors of Organization Adoption of E-government Cloud," in International Conference on Financial Management, Education and Social Science (FMESS), 2017, no. Fmess, pp. 283-288, doi: 10.25236/fmess.2017.60.

[30] R. V Krejcie and D. W. Morgan, "Determining Sample Size For Research Activities, Educational And Psychological Measurement,” Educ. Psychol. Meas., no. 30, pp. 607-610, 1970, doi: 10.25236/fmess.2017.60.

[31] P. Gupta, A. Seetharaman, and J. R. Raj, "The usage and adoption of cloud computing by small and medium businesses," Int. J. Inf. Manage., vol. 33, no. 5, pp. 861-874, 2013, doi: 10.1016/j.ijinfomgt.2013.07.001.

[32] H. Gangwar, H. Date, and R. Ramaswamy, "Understanding determinants of cloud computing adoption using an integrated TAM-TOE model," J. Enterp. Inf. Manag., vol. 28, no. 1, pp. 107-130, 2015, doi: 10.1108/JEIM-082013-0065.

[33] J. W. Lian, "Critical factors for cloud based e-invoice service adoption in Taiwan: An empirical study," Int. J. Inf. Manage., vol. 35, no. 1, pp. 98-109, 2015, doi: 10.1016/j.ijinfomgt.2014.10.005.

[34] J. W. Lian, D. C. Yen, and Y. T. Wang, "An exploratory study to understand the critical factors affecting the decision to adopt cloud computing in Taiwan hospital," Int. J. Inf. Manage., vol. 34, no. 1, pp. 28-36, 2014, doi: 10.1016/j.ijinfomgt.2013.09.004.

[35] R. Rufín, F. Bélanger, C. M. Molina, L. Carter, and J. C. S. Figueroa, “A cross-cultural comparison of electronic government adoption in Spain and the USA," in Technology Adoption and Social Issues: Concepts, Methodologies, Tools, and Applications, IGI Global, pp. 476-493, 2018, doi: 10.4018/ijegr.2014040104.

[36] Hair, T. M. Hult, C. M. Ringle, and M. Sarstedt, "A primer on partial least squares structural equation modeling," 2nd ed. Thousand Oakes, 2017.

[37] M. Kayali and S. Alaaraj, "Adoption of Cloud Based E-learning in Developing Countries : A Combination A of DOI, TAM and UTAUT," Int. J. Contemp. Manag. Inf. Technol., vol. 1, no. 1, pp. 1-7, 2020.

[38] S. Alaarj, Z. A. Mohamed, and U. S. A. Bustamam, "The Effect of Knowledge Management Capabilities on Performance of Companies : A Study of Service Sector," Int. J. Econ. Res., vol. 14, no. 15, pp. 457-470, 2017.

[39] A. Ayoub, R. Najat, and A. Jaafar, "A lightweight secure CoAP for IoT-cloud paradigm using elliptic-curve cryptography," Indones. J. Electr. Eng. Comput. Sci. (IJEECS), vol. 20, no. 3, pp. 1460-1470, 2020, doi: 10.11591/ijeecs.v20.i3.pp1460-1470.

[40] S. Ouhame and Y. Hadi, "Enhancement in resource allocation system for cloud environment using modified grey wolf technique," Indones. J. Electr. Eng. Comput. Sci. (IJEECS), vol. 20, no. 3, pp. 1530-1537, 2020, doi: 10.11591/ijeecs.v20.i3.pp1530-1537.

[41] F. H. Mohammed Jawad and H. H. M. Jawad, "Economic challenges of cloud computing in Iraqi educational institutions using exploratory analysis," Indones. J. Electr. Eng. Comput. Sci. (IJEECS), vol. 21, no. 1, pp. 566-573, 2021, doi: 10.11591/ijeecs.v21.i1.pp566-573. 